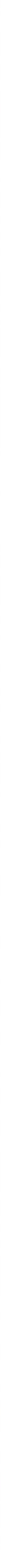




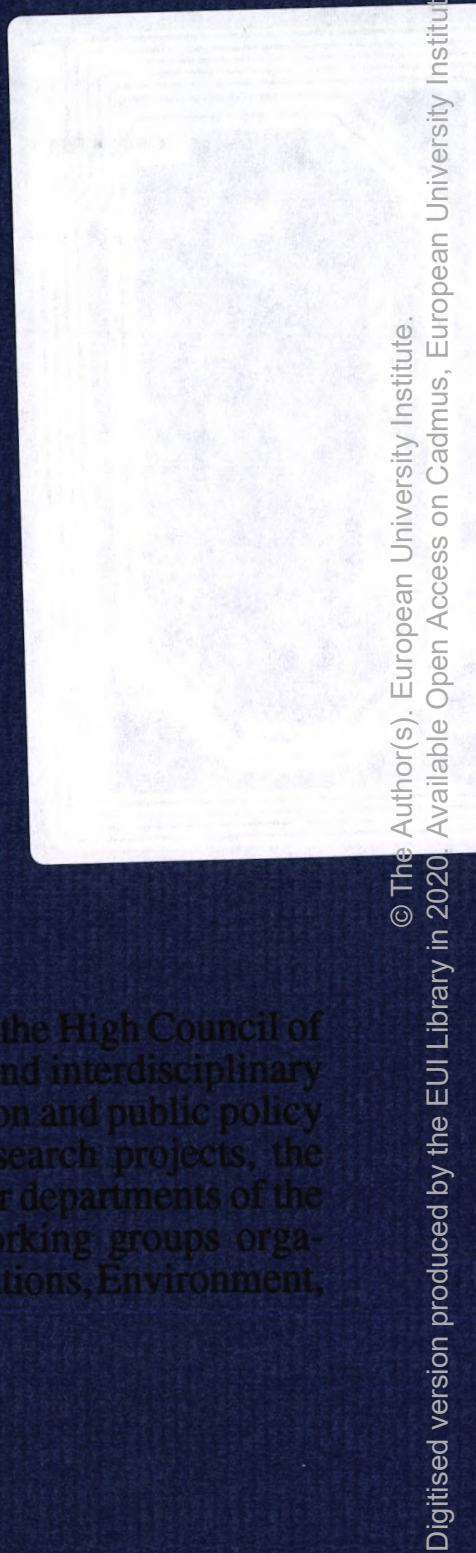




\section{EUROPEAN UNIVERSITY INSTITUTE, FLORENCE \\ ROBERT SCHUMAN CENTRE}

Convergence Bands:

A Proposal to Reform the EMS in the

Transition to a Common Currency

ENRIQUE ALBEROLA ILA

$$
\begin{aligned}
& \text { WP } \\
& 321.0209 \\
& 4 \text { EUR }
\end{aligned}
$$

EUI Working Paper RSC No. 94/6 
All rights reserved.

No part of this paper may be reproduced in any form without permission of the author.

\author{
(C) Enrique Alberola Ila \\ Printed in Italy in June 1994 \\ European University Institute \\ Badia Fiesolana \\ I - 50016 San Domenico (FI) \\ Italy
}




\title{
Convergence bands: A proposal to reform the EMS in the transition to a common currency
}

\author{
April 1994 \\ Enrique Alberola lla \\ European University Institute \\ Florence, Italy \\ Via dei Roccettini.9 \\ 1-50016 S.Domenico di Fiesole \\ Fax: $39-55-599887$ \\ E-Mail IALBEROL@ECOLAB.IUE.IT
}

\begin{abstract}
The European Monetary System (EMS) has recently gone through the worst crisis since its creation. Especially disturbing are the effects of the crisis on the central role that the Maastricht Treaty reserves for the EMS. This period of crisis has shown the unsuitability of the EMS as a mechanism to lead the European currencies towards Monetary Union. As a consequence, different proposals have been put forward to reform the EMS or substitute it for alternative arrangements. This article contains an additional contribution to the debate on how to proceed ahead. The convergence bands proposal advocates for a reform of the EMS, which renders the system more flexible. Flexibility is implemented through a continuous correction of the central parities and variable band widths, according to an index of fundamentals. Some examples show the working of the convergence bands which, in our opinion, could facilitate a smooth transition to EMU.
\end{abstract}

The author acknowledges the valuable comments of Mark Salmon and the financial support by Fundacion Ramon Areces. 


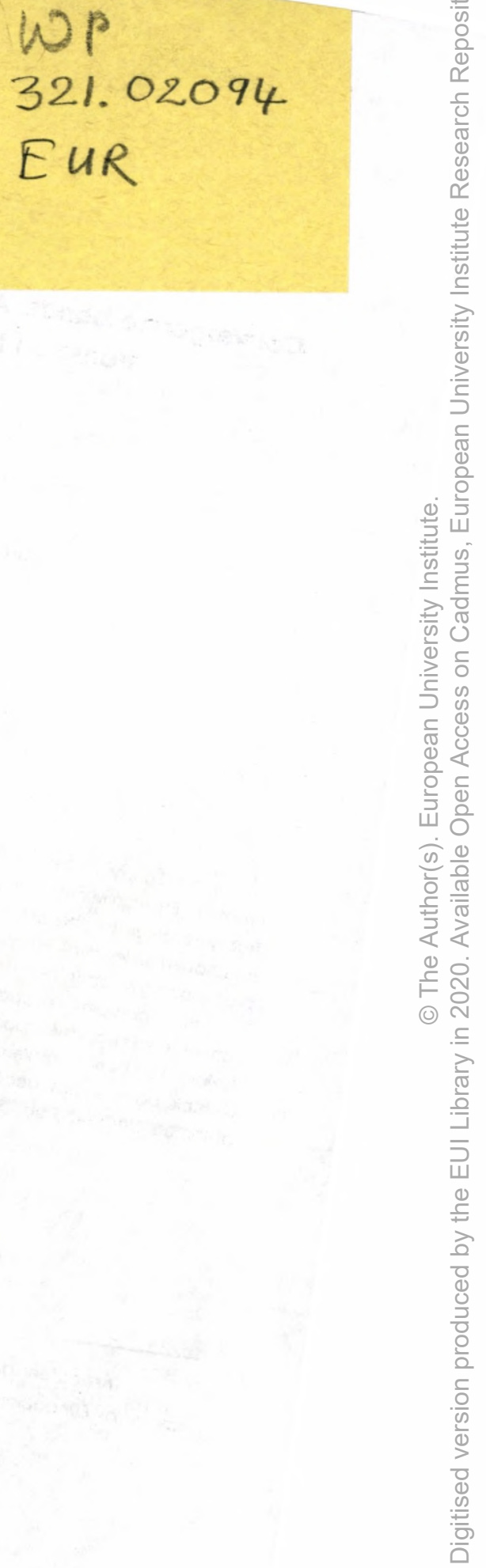


The European Monetary System (EMS) has recently gone through the worst crisis since its creation. The consequences have been far reaching and doubts have risen about the feasibility and even the suitability of proceeding with European Monetary Union (EMU) scheduled in the Maastricht Treaty.

Especially disturbing are the effects of the crisis on the central role that the Maastricht Treaty reserves for the EMS. The EMS is intended to be the exchange rate framework for the convergence process in the transition period. However, this period of crisis has shown the unsultability of the EMS to lead the European currencies towards the EMU goal. As a consequence, different proposals have been put forward to reform the EMS or substitute it for alternative arrangements.

This article contains an additional contribution to the debate on how to proceed, in the light of the previous crises and the functioning of the EMS. It is divided into four sections. The two first sections serve as a introduction to the proposal which is presented in the last two sections.

A concise account of the EMS record and the recent crisis is presented in section I, in order to highlight the long and short run factors which triggered the turmoil. In particular, the dangers of large exchange rate misalignments, which the current structure of the EMS allows, are illustrated through a simple model. Section II summarizes the proposals which have been made up to now to reform the system. The objective of this section is to explore the reasons for maintaining the exchange rate tool in the transition period; thus, a review of the optimum currency literature is carried out in the context of the European experience.

The conclusions derived from these two sections allow us to list the elements which a reform of the EMS should contain; they are presented in section III. Finally, a blueprint of our 'convergence bands' proposal is suggested in section IV. This proposal advocates a reform of the EMS, which renders the system more flexible. Flexibility is implemented through a continuous correction of the central parities and variable band widths, according to an index of fundamentals. The system avoids large exchange rate misalignments and grants a progressive hardening of the bands, as long as convergence is achieved. An 'entry clause' could be added to the rules, such that countries which attain convergence can enter the monetary union automatically. Some examples illustrate the operation of the convergence bands proposal. 
Convergence bands, in our opinion, render the system more transparent, in the sense that the costs of loose economic policies would be known. Thus, free-rider type behaviour would be ruled out and this would encourage coordination and promote the credibility of the system. Furthermore, the system allows bounded overvaluations which can foster convergence and can help to facilitate a smooth transition.

\section{I-The EMS experience and its turbulent end}

The EMS experience has been thoroughly analysed (see Giavazzi et. al. (1988), Gros \& Thygesen (1992), Goldstein et. al (1993), etc), so here we only provide a summary, stressing the main reasons which, in our view, provoked the collapse of the system.

Regarding the explicit targets of providing exchange rate and price stability to the EU countries, it can be considered a successful experiment. An additional role was implicitly given to the EMS by the high inflation members of the system (let us denote them as periphery countries) in that it should also be the vehicle by which convergence with low inflation countries would be achieved (core countries). This goal relied on the possibility of borrowing antinflationary reputation from the core countries in order to reduce their domestic inflation rates. However, this implicit goal has been only partially achieved, and inflation rate differentials persists.

\section{The tricky success of the EMS}

The development of the EMS can be broadly divided into two different periods, before and after the Basel-Nyborg Agreements of 1987. During the period between 1979 to 1987 the EMS behaved as a 'de facto' crawling peg regime, where frequent realignments adjusted inflation differentials. Thereafter, the EMS survived for more than five years without realignments, until the successive exchange rate crises which started in September 1992.

This long period of fixed exchange rates has been called the 'new EMS' by Giavazzi \& Spaventa (1990). These authors stress the stability of the exchange rate despite the deepening in the integration of the financial markets and the persistence of divergences in the periphery economies. The parities of these countries' currencies were perceived by the market to stay fixed in the medium-run; at the same time, the attempt by the authorities to reduce the remaining divergences in the fundamentals provoked the 
implementation of restrictive monetary policies; the resulting interest rate differentials led to an important inflow of capitals to these countries which kept their currencies in a strong position, despite being intrinsically weak currencies, which implied they were bound to be devalued in a future realignment.

How can this paradox be explained?; in other words, why did the markets rely on the short and medium run stability of these currencies?. Portes (1993) asserts that the EMS has benefitted from the 'convergence play': the market has bet on the sustainability of the parities as long as advances in the convergence among the economies were being observed. The market judgment that the periphery countries were on a good track to achieve convergence dismissed fears of a short run realignment. Furthermore, high inflation countries were eager to keep a strong currency in order to fully benefit from the borrowed reputation. The loss of competitiveness derived from the overvaluation of their currencies was regarded not only as acceptable but also was considered an additional mechanism to reduce further the inflation differentials. Markets and governments expected that the outcome of this strategy would be the following:

"A country which fixes its exchange rate, starting with higher inflation than its trading partners, will initially further lose competitiveness and experience an increase in unemployment. ...Eventually, inflation will become less than foreign inflation, competitiveness will improve, demand will increase and the economy will return to full employment, competitiveness, low inflation and a strong currency." [Quoted from Blanchard \& Muet (1993), who were referring to the French experience]

However, when advances in convergence slowed down or were reversed, expectations on the feasibility of the outcome changed and eroded the credibility of the system.

All in all, the apparent success of the new EMS in a situation of economic expansion and other exogenous factors, as the events of the Eastern Europe, created a wave of Europtimism, which accelerated the EMU project. This project was launched with the approval of the single Act in 1986 and sanctioned with the signature of the Maastricht Treaty in December 1991. In this context, periphery governments waved as a political success the strength of the currencies with respect to the.DM and the boost of capital inflows.

This identification of currency stability with successful policy making has 
two dangerous implications: first, short term reduction of inflation may distract governments from seriously tackling the structural sources of divergence (rigidity in the labour market, public finances, sheltered service sectors); second, in a recession context, as other indicators such as current account, unemployment, fiscal deficit, etc. deteriorate the defence of the currency becomes an essential political asset of the Government, which they are not willing to lose. Only when other disequilibria become unsustainable or socially unacceptable is the commitment of the Governments to defend the parities put at stake. This last point will play an important role in the EMS crises, as we point out below.

As tensions were building up, the Maastricht Treaty sanctioned the central role of the EMS in the transition to EMU. Indeed, the common currency is scheduled to evolve in stages from the current system, through a hardening of the bands. Clearly, this responsibility was not well suited to the system, since it has fallen apart less than a year after Maastricht. As a matter of fact, there seems to be a clear link between Maastricht and the collapse of the system, a point to which we will return below. The dream of a common currency, became a nightmare when Europe took up the commitment to turn it into reality.

\section{The EMS collapse}

The massive speculation against the periphery currencies of the EMS made the defence of the parities unsustainable and caused the collapse of the system. From this perspective, the financial system can be considered the killer of the system; this interpretation would endorse the theory of 'financial complot' advanced during the crisis by some official sources. But this is a very superficial picture of the problem which misses the underlying reasons for the attacks; indeed, financial market agents were the executioners of a sentence that the circumstances and the very same EMS structure had ensured. In any case, before going further it is convenient to underline some points regarding the role of financial markets (for a more detailed account, see Goldstein et al. (1993)).

In the first place, the complete liberalization of financial markets in most of Europe allows very fast portfolio shifts; in the second place, the exponential growth and increasing sophistication of financial instruments dwarfs the relative importance of Central Banks in the-foreign exchange markets. Both factors reduce the power of the Central Banking System to counteract speculation, 
both through direct intervention or the imposition of capital controls. Hence, the financial markets have indeed the power to destabilize the exchange rate, once the participants bet on the same direction of change. The crucial question to answer is then why they did so at the time they did.

First of all, there were objective reasons from an economic point of view for a speculative attack, due to the exchange rate misalignments and other economic imbalances accumulated in five years without realignments. It is crucial to note that the accumulation of misalignments is an intrinsic characteristic of the system after 1987, since fixed exchange rate bands coexist with divergences in the fundamentals.

The appendix presents a model of agents with heterogeneous beliefs, in which a target zone is established between diverging economies. The model shows that the target zone does in fact allow the accumulation of large exchange rate misalignments, while granting exchange rate stability. This model illustrates a feature of the post-' $87 \mathrm{EMS}$ : the target zone, when credible permits the overvaluation of the periphery currencies; this overvaluation can be beneficial to reduce divergences, such that the convergence play is sustained, but the system will eventually collapses.

Note that the outcome of the model illustrates a perverse mechanism built in the EMS; stability is achieved on the face of increasing exchange rate imbalances. These imbalances have to be corrected sooner or later, that is, as periphery countries climb ladders and become more and more confident, the system is also breeding the snakes which will provoke the collapse.

The situation of disequilibrium was especially evident for Italy, Spain and the United Kingdom at the time of the crisis but there remain doubts for the other countries of the system (see Eichengreen \& Wyplosz (1993)). However, these disequilibria also existed when financial markets were still endorsing the strength of overvalued currencies: the exchange rate was effectively on a bubble which sooner or later had to burst, forcing the the exchange rate to return to equilibrium'. What made it explode?

The collapse of the system in the theoretical model is endogenous; in reality, it comes about when a series of circumstances or events (call them credibility shocks) deteriorate the confidence of the market in the central

\footnotetext{
1. There has been an important amount of research devoted to explain the persistence of exchange rate disequilibria by exploring the significance of trends (chartism), herding behaviour, self-sustaining expectations or fads in the foreign exchange both empirically (Allen \& Taylor (1989), Frankel \& Froot (1987)) and with different theoretical models (Frankel \& Froot (1988), De Long et al. (1990), Kirman (1993), Bickchandani et al. (1993), etc.).
} 
parities. The change of mood in the financial markets provoked by the credibility shocks rapidly spreads and results in a speculative attack which the Central Banks are unable to sustain either through official communiques nor interventions in the foreign exchange.

The first shock hitting the system goes back to 1990, the date of German unification. The fiscal stance in West Germany translated into domestic inflationary pressures. It is opportune to mention that at the time, most academics favoured a revaluation of the DM with respect to the rest of the EMS currencies. Germany even asked for it, but this petition was rejected by the partners (especially France). Why?. On the one hand, there was a false sense of security and overconfidence which had grown with time; on the other hand, exchange rate stability had by that time become the cornerstone of domestic economic policies.

At this stage economic recession was starting to bite elsewhere in Europe. The seed for policy conflict was sown, when the Bundesbank aimed at controlling inflation at a time when other governments were eager to reduce interest rates in order to promote economic activity. At this point, the partner countries of Germany in the EMS had to choose between following German discipline or tackle domestic recession by reducing interest rates, which would imply an exchange rate realignment. Doubts on the final choice alerted financial markets, although official declarations continued to be firm on the exchange rate commitment.

The strains were exacerbated when the Maastricht Treaty was signed and economic conditions for joining the common currency were included. The convergence criteria were pushed ahead by Germany, who feared the merger of its solid Deutsche Mark and its tough Bundesbank, with less strict Central Banks and weaker currencies. Thus, the German gradualist approach, also called coronation theory, was imposed in the Maastricht Treaty: countries would enter the currency union only when they had converged to the German levels, or, as it has turned out to be the case in practice, beyond the German levels; i.e., the privilege to share a currency with Germany would only be granted to those who proved to be 'more German than the Germans'.

The convergence criteria contained in the Treaty are very tough and unrealistic. The inclusion in the Treaty of a 'last realignment' clause also contributed to destabilizing the system. The convergence criteria appeared to be clearly unattainable and were highly criticized even before the crisis (Begg et al. (1991)); they introduced uncertainty over the ability of countries to achieve these difficult goals, increasing the scope for the failure of the EMS. 
The final realignment clause made the market agree that a realignment would take place in the future with certainty (Giovannini (1993)). Both factors contributed to create the consensus that the system was becoming fragile and invited bets on the unsustainability of the parities.

At this stage, the gains from the convergence play were becoming a burden for the periphery economies given that, in anticipation of a future realignment, investors started to repatriate capital which they had invested in the previous years. Finally, as recession deepened in Europe and inflation failed to be controlled in Germany, there came the Danish and French referenda, which showed the political difficulties of pushing Maastricht ahead and convinced the markets that the benefits of keeping the parities could not offset the costs of maintaining high interest rates. Alea iacta erat.

After the first crisis in September 1992, when UK and Italy abandoned the system and Spain devalued the Peseta, more episodes of instability followed (Peseta, again, and Escudo devaluation in November 1992, Irish Punt in January 1993) until the system eventually broke down 'de facto' in August 1993, when parities were allowed to float in a $30 \%$ band. At the time of writing, no schedule for the return to the old bands and the reincorporation of the Lira and the Pound to the system have been proposed.

\section{II-From here to EMU: an analysis of the options}

Despite this period of monetary turmoil, the Maastricht Treaty has been finally ratified with no major modifications. Actually, the prospects for a reform of the EMS which were declared in the aftermath of the crises have faded and the EU Council appears to endorse the schedule fixed in the Maastricht Treaty, together with the convergence criteria, hardening of the EMS and Monetary Union for the qualified countries by the end of the century. Not even EU officials and most politicians believe that these plans can be fulfilled.

The official view rightly stresses that the situation is better than before the crises: first, the large devaluations have restored the equilibrium exchange rates; second, the crisis may have been helpful to indicate the countries which may converge, as Dornbusch (1990) suggested; finally, the worst of the recession seems to be over. All these factors might clear the horizon of some of the obstacles and make the eventual EMU target feasible.

However, serious doubts remain. First, it is not clear how the credibility of the system can be restored in the short term. The reaction of the market to the restoration of the old bands is feared because the concern exists that the 
agents will test the commitment of the authorities when it is achieved. Second, even if the new system were to be stable, why should it promote more discipline than before?. The nominal convergence criteria impose serious adjustments in most of the countries which will be costly in terms of real variables. In this context, would it be preferable to have an additional instrument in the transition period by leaving the exchange rates to float? that is, is a target zone desirable in the transition?. The answers to these questions have given rise to several alternatives to the Maastricht schedule and the EMS which we analyse now.

\begin{tabular}{|c|c|c|c|c|c|c|c|c|}
\hline$t$ & $\begin{array}{l}F \\
R \\
E \\
E \\
F \\
L \\
O \\
A \\
T\end{array}$ & $\begin{array}{c}w \\
i \\
d \\
e \\
b \\
d \\
n \\
d \\
s\end{array}$ & $\begin{array}{l}e x \\
b \\
\\
c \\
r \\
a \\
w \\
l \\
i \\
n \\
g \\
\\
p \\
e \\
g\end{array}$ & $\begin{array}{l}J \\
C \\
0 \\
N \\
V \\
E \\
R \\
G \\
E \\
N \\
C \\
E\end{array}$ & $\begin{array}{l}p \\
r \\
e \\
c \\
c \\
r \\
i \\
s \\
i \\
s\end{array}$ & $\begin{array}{c}M \\
a \\
a \\
s \\
t \\
r \\
i \\
c \\
h \\
t\end{array}$ & $\begin{array}{c}t \\
w \\
o \\
s \\
p \\
e \\
e \\
d \\
s\end{array}$ & $\begin{array}{l}F \\
I \\
X \\
E \\
D \\
R \\
A \\
A \\
T \\
E \\
S\end{array}$ \\
\hline
\end{tabular}

The schema above summarizes the different solutions proposed for the exchange rate system to guide the transition towards the Economic and Monetary Union. Any of these alternatives could be complemented with additional measures which have also been suggested to improve the stability of the system: improvement of policy coordination, higher Central Bank autonomy, revision and strengthening of the intervention rules, regulation and taxes on speculative transactions, etc (see Goldberg et al. (1993), for a critical account).

Note that the options range from a return to the free float regime (greatest flexibility) to the early and irrevocable locking of exchange rate parities (highest rigidity). Between them, and from left to right, we can find the widening of the bands -i.e. the current EMS, with $30 \%$ fluctuation bands, the crawling peg which characterized the first period of the EMS; our proposal, that 
is, convergence bands, on which we will expand in the next sections; the EMS, prior to the crises, with no effective realignments and narrow bands; and the two-speed approach, where a Monetary Union is formed for the core countries of the system while the periphery countries continue with an adjustable peg.

Although every proposal aims at avoiding the exchange rate crises of the past two years, only the extreme options can, in principle, guarantee the absence of speculative attacks, either because there is no exchange rate parity to defend or because there is simply no exchange rate at all.

The proposals for exchange rate management basically differ in the degree of flexibility given to the exchange rate; consequently, each view gives a different role to the exchange rate in the transition process. The role is decreasing with the degree of flexibility. The choice to be made is then determined by the importance assigned to the exchange rate instrument in the transition period. We now consider the extreme solutions, in order to highlight the role of the exchange rate under each regime and briefly evaluate the reasons for keeping or relinquishing this policy instrument.

\section{Free float}

The issue of the return to a floating regime has a long monetarist tradition. Its supporters consider that the exchange rate is like any another price and should be settled by the forces of the market, which would determine its equilibrium value and would make it adjust in the face of real asymmetric shocks. Taking into account the deep adjustments necessary in several EU countries during the transition period, this argument would seem to have a logic. An independent economic policy may be desirable in the transition and fixing an exchange rate parity in a context of free capital mobility entails the subordination of, at least, monetary policy. Given the multiple policy goals to attain in a finite horizon, keeping one additional instrument would help to achieve these goals. In contrast, one of the Maastricht criteria is precisely to keep the exchange rate stable within the narrow band for two years, that is, the would-be instrument becomes an additional goal and this makes the fulfillment of the criteria even more complicated.

However, the period after Bretton Woods revealed the dangers of floating, when currencies became very volatile and deviated widely from their equilibrium values. This created great problems in the functioning of the Common Market and provoked the 'snake' experiment and finally the 
establishment of the EMS (see Giavazzi \& Giovannini (1989),ch.1, for a detailed record). Therefore, the institutional arrangements and high degree of integration of the European Community precluded a return to a free float regime. Furthermore, in a context of structural adjustments and recession, there exists the temptation to implement competitive devaluations which, followed by retaliation, could deteriorate the cooperative climate among the member countries. Finally, the loss of the exchange rate anchor would complicate the control of inflationary expectations in the periphery countries.

All in all, the free float option can be dismissed, although we should acknowledge the advantages of the exchange rate instrument in the transition process.

\section{Fixed rates and optimum currency areas}

The opposite view is represented by the early locking of exchange rates and the adoption of a common currency (Giovannini (1991), among others). This implies the complete loss of the exchange rate and the monetary policy, already very limited in the EMS. The two-speed track (Dornbusch (1991)) to Monetary Union is a variant of this idea: monetary union could initially consist of the core countries of the system, and periphery countries would be let in as they catch up. This idea is gaining support in official and academic circles that realize the difficulties of forming a common currency that includes all the countries of the Union. However, it faces political difficulties.

Clearly, a move to a common currency would foster coordination of economic policies and eliminate exchange rate movements. The supporters of this fast track to EMU stress the problems of the coronation theory embraced by the Maastricht Treaty: as long as there are convergence requirements to be met, there exist problems of credibility and the transition of the periphery economies is uncertain (see, for instance, Begg et al. (1991)). EMU would suppress this uncertainty and convergence would be faster within a Monetary Union.

The key questions are how large would be the costs of this 'shock therapy' and whether these costs are sustainable by the individual countries, or the EU as a whole. In other words, what would be the costs of renouncing one's own currency?. We can identify on the one hand a political cost, linked to the issue of sovereignty, which has been mainly stressed in Germany. Without dismissing the political component, which will reappear below, we have more interest in the economic payoffs of this option. 
The compensations for the loss of the exchange rate instrument and the autonomy of monetary policy are given by the gains in efficiency, loss of uncertainty, economic power and antinflationary reputation. Many of the costs and benefits are very difficult to evaluate. The Cecchini Report (1988) and Emerson et al. (1991) are biased attempts to measure the microeconomic costs and benefits. Besides many of the benefits and costs will only be realized after the step to merge the currencies has been taken.

The macroeconomic payoff is even more complex to compute. The prospect of EMU has revived the interest in the Optimum Currency Areas (OCA) literature, which provides the framework to analyse these macroeconomic aspects. The value of the exchange rate instrument basically depends on its 'a priori' utility and its actual effectiveness. Here we attempt a very brief approximation of these issues, mentioning the basic references to be found in the OCA literature (for a general account, see Ishiyama (1975); in a European context, De Grauwe (1992)).

'A priori' utility: As mentioned above, the exchange rate can help in the adjustment to asymmetric shocks. Therefore, the first question to consider is their likelihood. Asymmetric shocks are more likely the lower the degree of economic and financial integration, and product diversification (Kenen (1969)) The Common Market and then the Single Market have contributed to integrate the european economies, but there is still much scope for asymmetric shocks, as Eichengreen \& Bayoumi (1992) show.

Secondly, following the seminal contribution by Mundell (1961), the exchange rate acts as a surrogate to factor mobility. Since labour mobility in the EU is very low (Eichengreen (1991)), giving up the exchange rate would have a high opportunity cost. Therefore, the exchange rate would be 'a priori' useful in the transition process.

Exchange rate effectiveness. Nevertheless, the effectiveness of the exchange rate as an adjustment instrument has also to be proved. The proof is controversial and is linked to the deeper question on how effective monetary policy is considered to be in general. In any case, it should be recognized that the exchange rate can facilitate the structural adjustment; but, as we noted above this may open the field for damaging competitive devaluations. In a context of very open economies, with high vulnerability to exchange rate movements (McKinnon (1963)), the potential harm may call for some sort of exchange rate arrangements, like the EMS.

One further consideration to be made before reaching a final conclusion 
regards the institutional framework of the EU. The adoption of a common currency would cause large regional disequilibria and adjustment problems. These regional imbalances could be overcome if the appropriate economic transfer schemes were arranged; however, the foreseeable magnitude of these transfers largely exceeds the capacity of the EU current institutional mechanisms, which are largely discretionary. Sachs and Sala-i-Martin (1991) in an empirical study show that Europe can hardly compensate for asymmetric 'regional' shocks, in comparison to the USA. Indeed, a federal fiscal system

similar to the one functioning in the United States should be set up beforehand, but this implies a long political process. Consequently, the political component comes to the front of the stage again. As Goodhart (1975) already noted and Braga de Macedo (1991) has reminded, the feasibility of a Monetary Union is essentially based on the degree of social cohesion and interstate solidarity. Surely, Europe is far from having achieved it.

All in all, the evidence is that the EU is far from an optimum currency area and that deep structural adjustments are still required. Since the necessary compensation mechanisms still have to be provided, the move to a single currency in the present circumstances is inappropiate. Thus, we think that the exchange rate can play a role in the transition period, albeit in the context of some exchange rate arrangement.

\section{III-Ingredients for a reformed EMS}

The brief account of the EMS and its crisis has stressed the difficulties and underlying tensions of the system. The collapse of the EMS leaves no scope for optimism regarding the EMU horizon scheduled in Maastricht. At the moment, there is an impasse which reveals serious doubts on how to proceed, and no alternative out of the current floating seems feasible. Under these circumstances, it seems clear to us that Monetary Union will be postponed.

The lessons that this distressing period has provided should be assimilated in order to set up the means and mechanisms to attain effective convergence at the lowest possible cost.

Our proposal lies at the middle point between the two options which have been analyzed and aspires to reap the benefits of both without incurring their costs. We endorse the view that a exchange rate mechanism is necessary in the transition, but the EMS has to be reformed to deliver convergence. Thus, 
we suggest a gradualist approach, but in the context of a reformed EMS. The aim of the system should be to provide both stability and convergence, so we advocate that flexible bands (convergence bands) substitute the fixed bands of the EMS. Albeit recognizing the dangers of the coronation theory, we consider too abrupt a direct adoption of a common currency by the whole EU at the present moment, although we would support a multispeed approach, if politically feasible.

Now we sum up the ingredients which a reformed EMS should contain, such that the tensions which provoked the crisis could be avoided. A detailed description of the regime proposed is given in the next section.

A pre-condition for reform is that economic realism takes some weight out of political pragmatism. Some parities had become completely unreasonable; in spite of it, the authorities of the periphery countries were very reluctant to realign, for the reasons pointed out above. As a result, the countries which were not disciplined, were free riding on the stability delivered by the disciplined countries. Finally, this asymmetry brought about political strains, which further deteriorated the reputation of the system.

Moreover, the collapse of the EMS took place because it did not oblige to discipline enough the periphery countries and generated in these countries disequilibria which eventually became unsustainable. The discussion of optimum currency areas above stressed the need to achieve a certain degree of convergence before moving to EMU. This convergence should be not only nominal (as in the Maastricht Treaty) but also real, given the lack of compensation mechanisms of the EU; consequently, the exchange rate system should induce discipline to a greater extent than the EMS used to do. In fact, the honeymoon effect (sic) granted by a target zone induces undisciplined behaviour.

A carrot-and-stick strategy would be convenient to foster discipline and convergence. The costs of no-discipline should be made explicit and discipline should be rewarded. Thus, the system would become more transparent and free-riding problems would be overcome. This perceived fairness would make the system incentive compatible and would facilitate policy coordination among the member countries.

Moreover, if this perception of fairness is appreciated by the markets, the reputation lost in the recurrent crises could be rapidly rebuilt. However, reputation may not be enough in the presence of the large misalignments prompted by the fixed central parities. Thus, a final ingredient the reform 
should contain is a mechanism which allows greater flexibility.

The measures we are putting forward to make the system more flexible are expected to bring about the rest of elements.

\section{IV-Convergence bands for the EMS}

We propose a system of 'convergence bands' consisting of flexible central parities and variable bands of fluctuation plus a reinforcement of the intervention mechanisms and, eventually, other complementary measures.

The convergence bands alternative borrows some elements of Williamson's (1985) proposal for an exchange rate target zone, namely, the idea of central parities based on real exchange rates. Williamson proposed a World Monetary System in which real exchange rates were allowed to fluctuate within wide bands (10\%). The crucial point made by Williamson is that central parities for the nominal exchange rates were not fixed, but they would adjust for inflation differentials (or other fundamental index), such that large exchange rate misalignments were avoided. The goal of Williamson's target zone was to achieve exchange rate stability and incentive coordination among the economic blocs, but granting autonomy in their domestic policies but it lacked the convergence dimension which we also want to include.

The added value of our proposal is to build in a mechanism which encourages convergence in the economies, on the basis of the elements mentioned above.

\section{Structure of the target zone}

The changes of the system do not imply changes in the Exchange Rate Mechanism (understood as ECU composition, parity grids, etc.), but only on the EMS structure: central parities, bands of fluctuation and intervention rules.

-Central parities should be corrected according to the expectations of the evolution of the fundamentals of each country. An index of fundamentals can be constructed in many different ways. Considering Maastricht convergence criteria, adding other macroeconomic indicators or, more simply, taking into account inflation differentials. An independent central authority (a Committee within the European Monetary Fund?) should determine quite often the necessary changes in the currency parities. When the effective evolution of the fundamentals varies from the expected one, it is corrected in 
the next period.

These rules do not imply that the central parity (c) is set equal to the expected equilibrium exchange rate $(\bar{s})$, but rather that it moves in its direction according, for instance, to a linear relation of the type $c=\beta(\bar{s}), \beta>0$. Since exchange rate overvaluations can exert an important domestic deflationary effect through the loss of competitiveness and cheap imports. Choosing a value for the parameter $\beta$ lower than one would provoke the overvaluation of the currency with respect to its central parity and this overvaluation would grant the deflationary effect.

The remarkable feature of this alternative is that the size of the misalignment is bounded by the wedge between the equilibrium exchange rate and the limit of currency appreciation, and it can be chosen and changed. In comparison, in the current EMS, $\beta$ can be seen as a dummy variable, equal to zero among regimes and with discrete jumps to one in the realignments ${ }^{2}$.

-The width of the fluctuation bands would be chosen in a similar way to the central parities, as a positive function of the expected divergence. A small additional margin of fluctuation could be allowed. Thus, a formula for the width of the bands can be established, too; letting $s^{+}$stand for the upper limit of fluctuation, we can write, $\left[s^{+}-c\right]=\gamma_{0}+\gamma_{1} \mu$ the rule could be corrected in periods of strain.

Both mechanisms would include a clause which adjusted for differences between expected and observed divergences.

-Finally, the intervention mechanisms should be reinforced, that is, there should be a stronger commitment of the Central Banks to intervene in defence of the parities, in order to improve credibility.

-The new rules could be complemented with other measures pointed out by the literature. In particular, greater Central Bank independence and restrictions on the movements of speculative nature.

The main aim of this additional flexibility is to rule out the accumulation

\footnotetext{
${ }^{2}$-In practice, less than one, since exchange rate realignments in the EMS have not completely corrected for inflation differentials.
} 
of excessive misalignments which make the band unsustainable. Consequently, the attacks on a particular currency would not be justified on a strictly economic basis, i.e. only purely speculative attacks would be possible. In this situation, the defence of reasonable parities would be easier because, as mentioned below, the core countries would be more willing to offset the speculative pressures.

But also note that the convergence bands, given the adjustment rules, impose a cost to the countries which are unable or unwilling to converge. What are these costs?. The constant (central parity) depreciation of the diverging currencies implies a cost for these countries (risk premium, increasing problems of controlling inflation, etc). Note further that the existence of the bands and the degree of freedom of each country can facilitate the implementation of adjustment programs. In this situation, the market view can play a stabilizing role because there exists the certainty that progresses in convergence, which will be accompanied by the strength of the currency; on the contrary, problems or obstacles of implementing the structural adjustments to convergence can cause the opposite effect.

This clear payoff could help to relieve underlying political tensions by solving the free rider problem. Moreover, the core countries would be more willing to defend the weak currencies in the event of an attack, both because the attack would be regarded as unjustified and because the periphery countries are not perceived to take advantage of the core countries. The system improves then its incentive compatibility and in this context, intervention rules could be realistically reinforced and a better climate for coordination could be achieved. The crucial point is to find a balance between promotion of convergence and exchange rate misalignments, which is given by the choice of $\beta$. A $\beta$ equal to one rules out misalignments, but it would deliver little room to promote convergence. A small $\beta$ would have opposite effects. Hence, the choice of $\beta$ is subject to bargaining among the member countries.

Once the balance is established, the convergence bands give the authorities some discretion during the transition period, but states clearly the costs of a too slow convergence, in terms of postponed adjustment an depreciation. We can assume that throughout the transition period different countries follow different trajectories: the most successful countries will be observed to narrow their bands and harden their parities while those lagging behind will keep wide bands.

As a corollary to the system, it could be established that countries would abandon the convergence bands and adopt a common currency, once they have hardened the position of their currency up to a determined threshold. 
This clause would introduce an additional factor of discipline in the system.

\section{Some examples}

Taking the model of heterogeneous agents presented in the appendix, we can briefly illustrate the workings of convergence bands.

The traditional EMS bands are substituted by our proposed convergence bands. We need to specify the parameter of adjustment $\beta$, for the central parity and a formula to determine the width of the band. We propose three examples, which simulate three different situations. The basic equations which determine the convergence bands are:

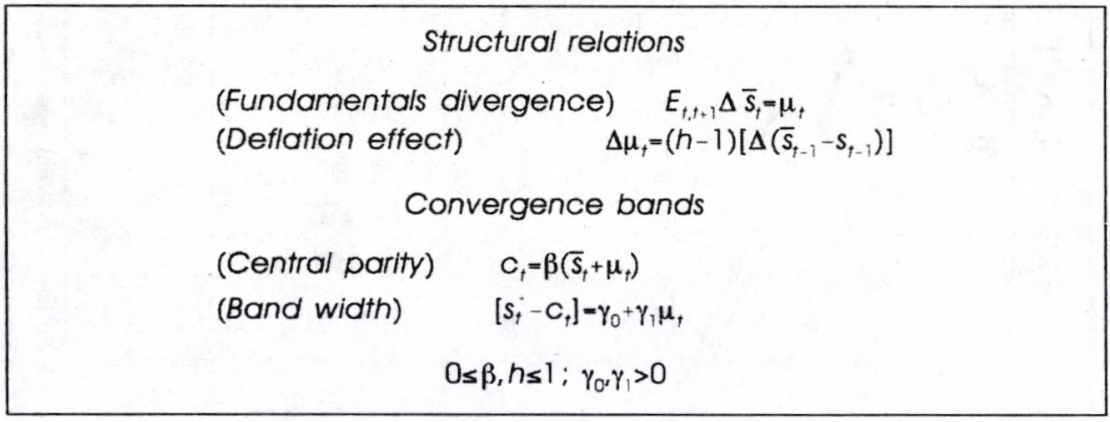

We have divided them into two categories: the structural relations of the economy, which determine the size of the divergence $(\mu)$ and the ability to converge (1-h), and the convergence band, consisting of the expressions for the degree of adjustment of the central parity $(\beta)$ and the width of the band $\left(\gamma_{i}\right)$. Changes in the equilibrium exchange rate $\bar{s}$ approximate inflation differentials, so that, $\mu$ is the expected inflation differential. If the deflationary effect of overvaluation is taken into account, the country is able to converge. More precisely, the inflation differential is reduced proportionally to the size of the overvaluation and by a magnitude which positively depends on the value of $(1-h)$, the deflator parameter. This, in turn is positively related to the degree of openness of the economy (For more details on these structural relations, see the appendix). The convergence bands have been explained above.

For simplicity, in the examples we propose the expected inflation differentials and the formula for the band width are equal in all the cases:

$$
\mu=2 \% \text { per year; }\left[s_{t}^{*}-c\right]=(0.5+2 \mu) \%
$$




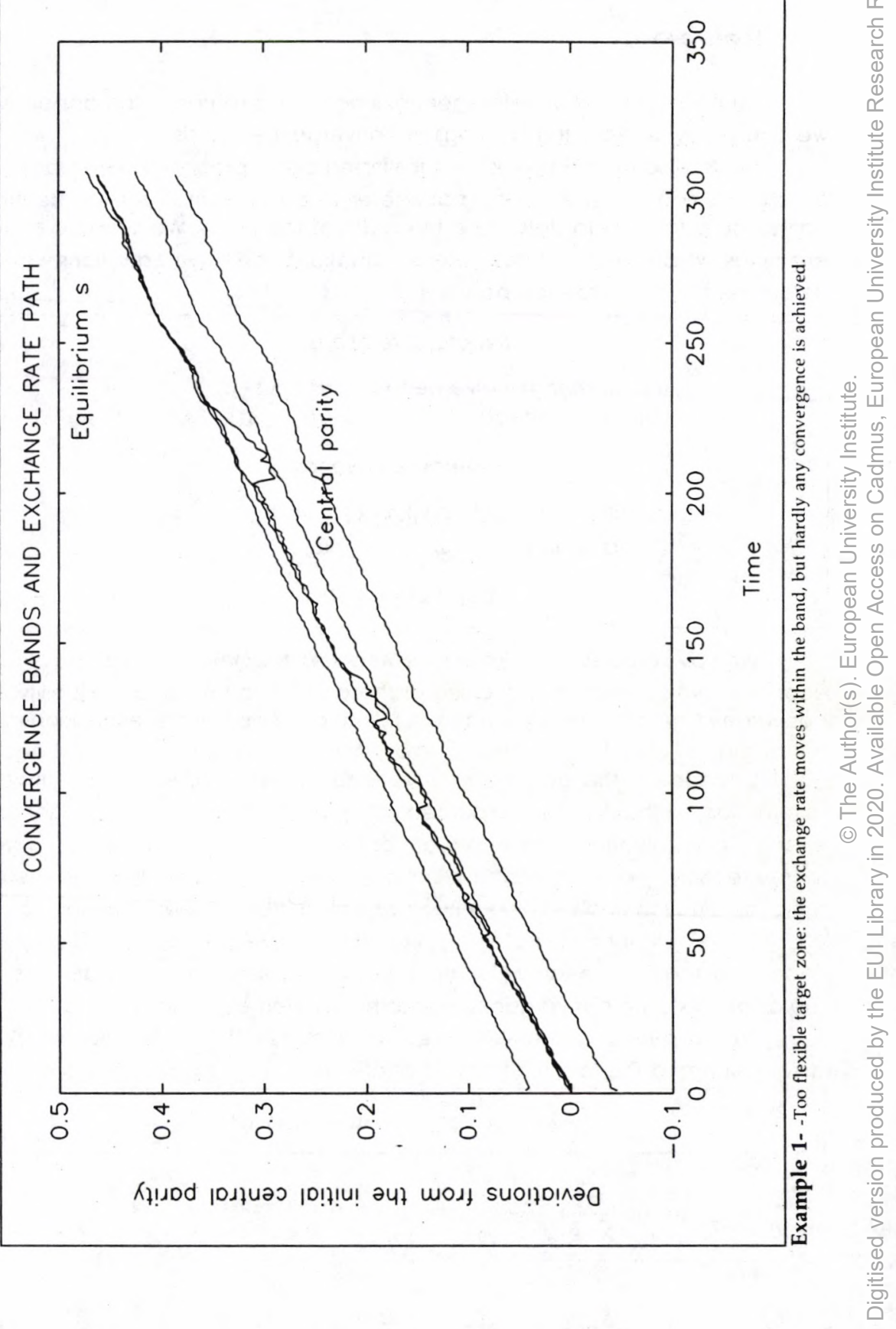




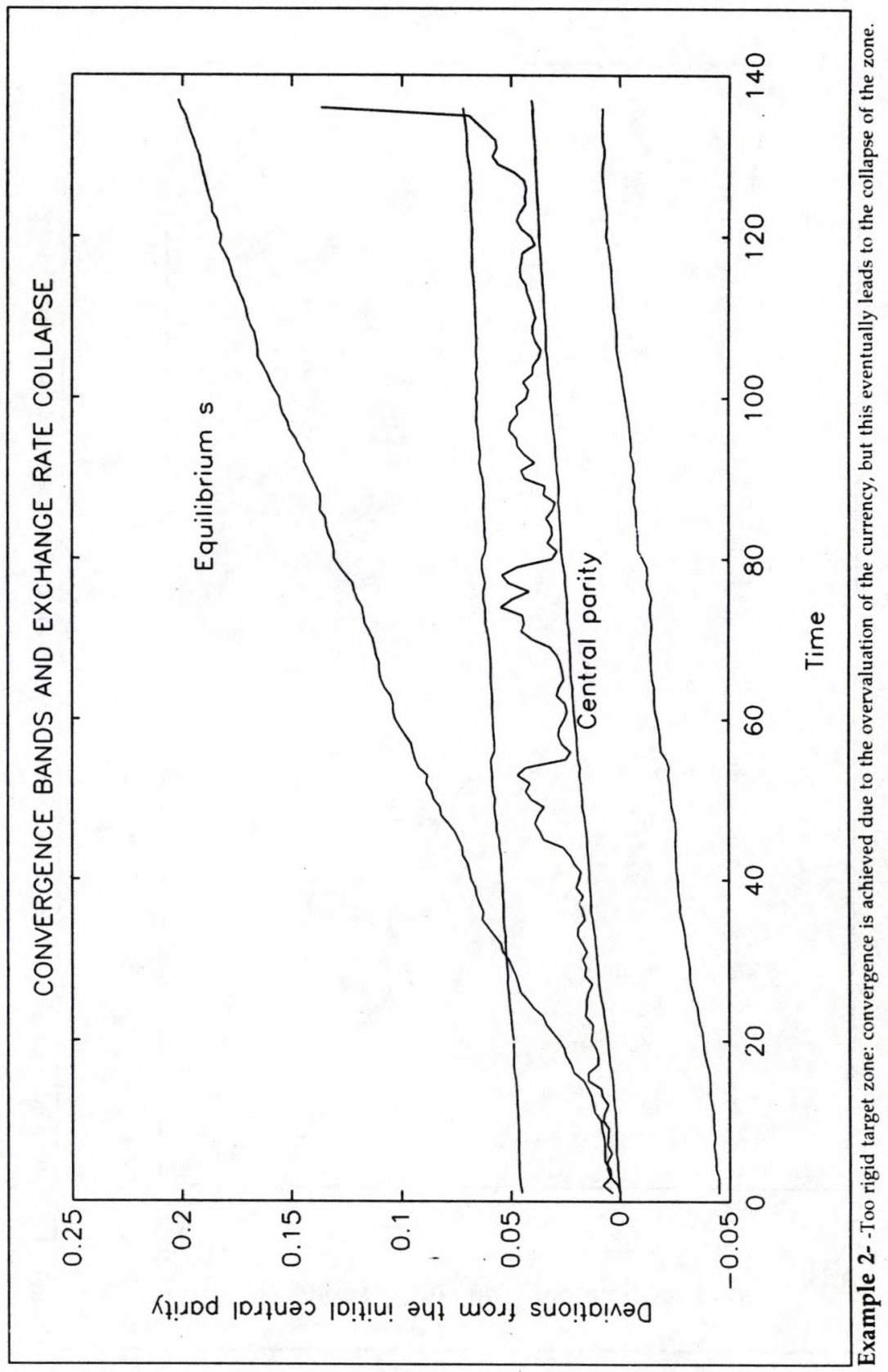




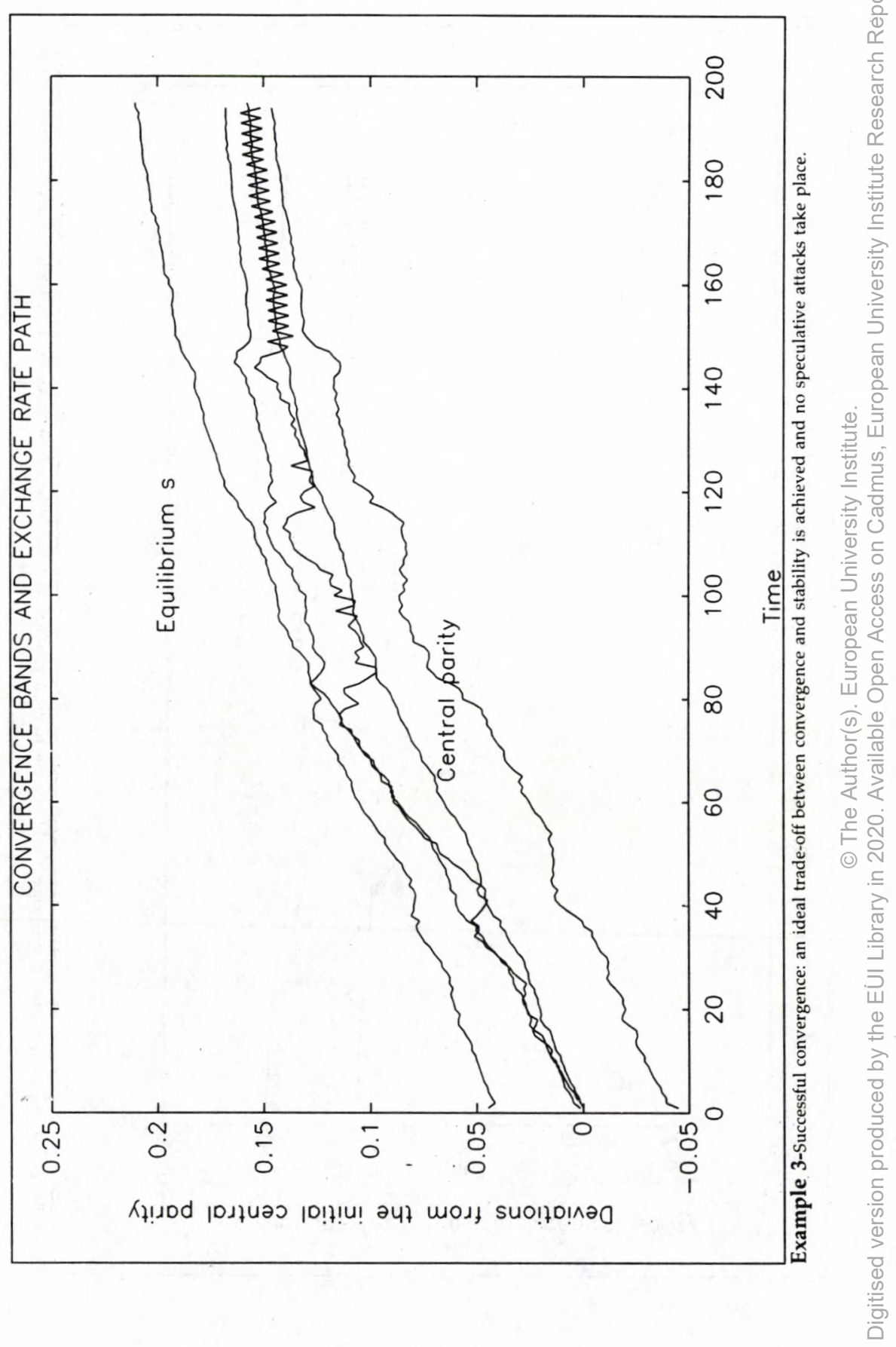


The outcome of the simulations then depends on the deflation parameter (1-h) and the choice of $\beta$.The figures show the different outcomes of the simulations.

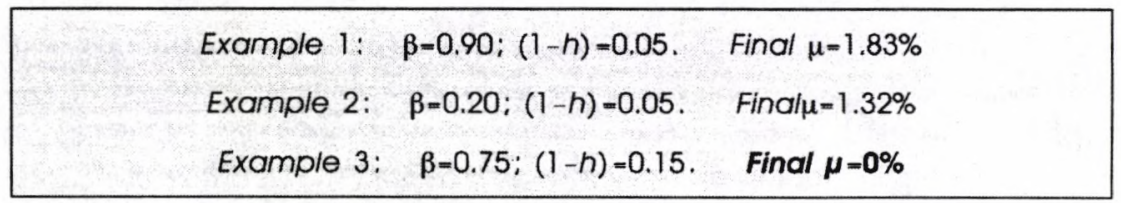

In the first example, the target zone is very flexible and allows for a very small overvaluation of the currency. As a consequence, its survival is guaranteed, because there are no exchange rate strains, but it can hardly deliver any convergence. The exchange rate follows an upward trajectory within the band, but it stays very close to $\bar{s}$. We stopped the process arbitrarily and computed the inflation differential at that period; $\mu$ was equal to $1.83 \%$, just 17 basis points less than in the initial period.

The second example, on the contrary, displays the effects of too rigid a target zone with low convergence capacity. In this case, the target zone grants a large overvaluation but it is not accompanied by a significant reduction in the inflation differentials. Therefore, the zone eventually collapses with no convergence $(\mu=1.32 \%)$.

Finally, the third example displays the successful case of convergence. The value of $\beta$ is quite high, but it grants significant deviations from the exchange rate equilibrium; on the other hand, the capacity to converge is higher in this economy, so that the overvaluation allows for a smooth reduction of the inflation differentials until convergence is achieved without problems of exchange rate stability. If the entrance clause is applied at this point, this currency would abandon the convergence bands regime and enter the currency union.

What conclusions can we draw from these examples? In the first place, convergence can be achieved within the system; but it should be observed that this outcome is only possible if there exists an adequate choice of the convergence band. The decision depends, as we have said above, on the bargaining process among the countries, but also, and more importantly, on the capacity of the countries to converge. Imposing a rigid target zone on a country with structural problems to reduce inflation would lead to future exchange rate crises, as showed in example 2. On the contrary, a too conservative convergence band may yield exchange rate stability, but it 
cannot be an instrument for convergence.

\section{Conclusions}

We have presented in this article a proposal to reform the EMS in the transition to the European Monetary Union. The adoption of convergence bands instead of the fixed bands of the EMS intends to provide more flexibility to the system in order to avoid exchange rate crisis, derived from the support of unrealistic parities. We also suggest that the new system can help to deliver convergence. Thus, the exchange rate becomes an instrument for convergence instead of a convergence goal, as in the Maastricht Treaty.

Despite the appeal that this contribution might have, we should make some additional considerations and recognize the limitations of this approach.

In the first place, while ruling out the main source of instability, the convergence bands do not guarantee the absence of speculative attacks, provoked by expected policy shifts (see Obstfeld (1986)) or other types of shocks not conveyed in the setting of the bands. For instance, the strains to which the French Franc was exposed in the recurrent crises of the EMS did not essentially reflect fundamental disequilibria, but rather the expectation that the French Government would eventually abandon its franc fort policy for the sake of a much needed reduction in the interest rates.

Nevertheless, the cooperation and coordination climate which the new system is assumed to establish could help to overcome these crises Furthermore, we should not forget that the EMS turmoil affected all currencies in a domino effect. First, the currencies with larger misalignments were attacked and beaten and after their success the speculators turned to all the currencies of the system, including the healthy ones. Our system, in principle, would avoid this sort of contagion, because there is scope for excessive misalignments

The possibility of purely speculative attacks on convergent currencies suggest a multi-speed approach to EMU, since this would completely rule out the attacks. We considered this strategy above, and the automatic entrance clause which we have contemplated also works in this direction.

The second set of considerations regards the feasibility of this system. We should be aware that technical difficulties could arise: how often to adjust, how to correct the deviations from expected inflation differentials, which body should determine the parities, how much scope to allow for discretion and how much for rules, how to channel the parities and so on. Besides there remains 
the question of the political feasibility of this option. While core countries might prefer it to the current EMS, the periphery might be reluctant to accept a system which imposes a cost on divergences. But they should also recognize the reputation gains that a good performance in this system would grant and the higher commitment from the core countries to defend the system. From this perspective, the goal to join the currency union would be perceived as costly but also as challenging, and this sense of challenge and the dangers of not facing it could stimulate the will to push ahead the necessary reforms.

\section{References}

ALBEROLA ILA,E. (1994)."How Long Can a Honeymoon Last?. Institutionalist and Fundamental Beliefs in the Collapse of a Target Zone". EUI, Mimeo.

ALLEN,H. TAYLOR,M.(1989)."Charts, Noise and Fundamentals: A Study of the London Foreign Exchange Market",CEPR Discussion Paper,n.341.

BAYOUMI,T. EICHENGREEN,B.(1992)."Shocking Aspects of European Monetary Unification".CEPR Discussion Paper, 643.

BEGG.D. F.GIAVAZZI, L.SPAVENTA, C.WYPLOSZ (1991).Monitoring European Integration. The making of Monetary Union.CEPR Report n.2

BIKHCHANDANI,G. D.HIRSHLEIFER, I.WELCH (1992)."A Theory of Fads, Fashion Custom and Cultural Change as Informational Cascades".Journal of Political Economy,v.100,n.5.

BLANCHARD,O \& J.P.MUET (1993)."Competitiveness through disinflation: an assessment of the French strategy", Economic Policy, 16.

BRAGA DE MACEDO, J.(1991)."Labour Mobility, Fiscal Solidarity and the Exchange Rate Regime: a Parable of European Union and Cohesion",EC Economic Papers, n.86

CECCHINI,P. (1988). The Cecchini Report. Commission of the European Communities. 
DE LONG,J.B. A.SHLEIFER, L.SUMMERS, R.WALDMAN (1990)."Positive Feedback Investment and Destabilizing Rational Speculation", Journal of Political Economy, v.98.

DE GRAUWE,P.(1992)."The Economics of Monetary Integration",Oxford University Press.

DORNBUSCH,R. (1991)."Problems in European Monetary Integration" in A.Giovannini, C.Mayer, European Financial Integration. Cambridge University Press.

EIChENGREEN,B. (1990)."Is Europe an Optimum Currency Area", CEPR Discussion Paper n.478.

EICHENGREEN,B. WYPLOSZ,C.(1993)."The Unstable EMS", INSEAD WP 93/38.

EMERSON,M. D.GROS, A.ITALIANER, J.PISANI-FERRY, H.REICHENBACH (1991). One market, One Money, OUP.

FRANKEL,J.A FROOT,K.A.(1988)."Chartists, Fundamentalists and the Demand for Dollars".Greek Economic Review.

FRANKEL,J.A FROOT,K.A.(1986)."Understanding the Dollar in the Eighties: the Expectations of Chartists and Fundamentalists", The Economic Record.

FRANKEL,J.A. FROOT,K.A.(1987)."Using Survey Data to Test Standard Propositions Regarding Exchange Rate Expectations".American Economic Review,v.77,1.

FROOT,K.A. M.OBSTFELD (1991)."Exchange Rate Dynamics under Stochastic Regime Shifts: An Unified Approach" Journal of International Economics,

GIAVAZZI,F. SPAVENTA,L.(1990)."The 'new' EMS" in P.De Grauwe L.Papademos eds. The EMS in the 1990s, Longman.

GIAVAZZI,F. GIOVANNINI,A.(1989).Limiting exchange rate flexibility. MIT press.

GIAVAZZI,F. MICOSSI,S. MILLER,M.(1988)."The European Monetary System". Cambridge University Press. 
GIOVANNINI,A. (1991). "Money Demand and integrated European Economy" European Economy, Special Issue n.1.

GIOVANNINI,A. (1993)."The Debate on Nominal Convergence before and after the 1992 Crisis", Mimeo.

GOLDSTEIN,M. D.FOLKERTS-LANDAU, P.GARBER, L.ROJAS-SUAREZ, M.SPENCER (1993). International Capital Markets. Exchange Management and Int.Cap.Flows.IMF. World Economic \& Financial Surveys

GOODHART,C. (1975).Money, Information and Uncertainty. MacMillan

GROS,D. THYGESEN,N.(1992). European Monetary Integration.Longman.

ISHIYAMA, Y.(1975)."The Theory of Optimum Currency Areas: A survey." IMF Staff Papers, 22.

KENEN,P. (1969)."The Theory of Optimum Currency Areas: an Eclectic View" in R.A.Mundell, A.K. Swoboda eds. Monetary Problems of International Economy. University of Chicago.

KIRMAN,A.(1993)."Ants, Rationality and Recruitment". Quarterly Journal of Economics,v.108.

KRUGMAN,P.(1991)."Target Zones and Exchange Rate Dynamics", Quarterly Journal of Economics,v.106.

MacKINNON (1963)."Optimum Currency Areas". American Economic Review,v.53.

MUNDELL,R.A. (1961)."Theory of Optimum Currency Areas". American Economic Review,v.51.

OBSTFELD,M. (1986)."Rational and Self-Fulfilling Balance of Payments Crises", American Economic Review,v.76.

PORTES,R.(1993)."EMS and EMU After_the Fall".World Economy,n.1 
SACHS,J. SALA-I-MARTIN,X (1991)."Federal Fiscal Policy and Optimum Currency Areas",CEPR Discussion Paper n.632.

WILLIAMSON,J.(1985)."The Exchange Rate System",Institute for International Economics, n.5

\section{Appendix: Collapse of a target zone in a model with heterogeneous expectations.}

This appendix presents a model of exchange rate determination with heterogeneous agents. This model illustrate collapses in a target zone, and will also be used to simulate exchange trajectories with convergence band. This model shows that divergences in the fundamentals accummulate in a exchange rate target zone as the EMS, among divergent economies as the EMS, leading to large exchange rate misalignments which finally provoke the collapse of the system. Here we only describe the model very briefly. In Alberola (1994) a more detailed explanation and a complete analysis of the results can be found.

The model. The equations of the basic model are:

Expectation formation equations

$$
\begin{aligned}
& \text { (market) } \quad \Delta s_{t, t-1}^{M}=w_{f} F_{t}+\left(1-w_{t}\right) l_{t} \\
& \text { (fundamentalist) } \quad F_{t}=\Delta s_{t, t, 1}^{F}=v\left(\bar{s}_{t}-s_{t}\right) \\
& \text { (institutionalists) } \quad I_{t}=\Delta s_{t, t, 1}^{\prime}=l\left[s_{t}^{\prime}\right] \\
& \text { (DLS fit) } \\
& \Delta w_{t, t+1}=\frac{X_{t}}{\lambda\left[\sum_{k=1}^{t-1} \lambda^{t-1-k} X_{k}^{2}\right]+X_{t}^{2}}\left(Y_{t}-W_{t} X_{t}\right) \\
& Y=\Delta S-F ; \quad X=F-I \text {. } \\
& 0 \leq W \leq 1 ; s \leq s^{\prime} \leq s
\end{aligned}
$$

Exchange rate motion equations

$$
\begin{array}{cc}
\text { (equilibrium rate) } & \bar{s}_{t}=\bar{s}_{t-1}+\mu+\varepsilon_{t} \\
\text { (effectiverate) } \quad s_{t}=s_{t-1}+\theta \Delta s_{t, t-1}^{M}+v_{t} \\
\varepsilon_{t} \sim N\left(0, \sigma_{\bar{s}}\right): v_{t} \sim N\left(0, \sigma_{s}\right)
\end{array}
$$


The first set of equations present how the expectations of the market are formed $\left(\Delta s_{t, t+1}\right)$, as a weighted average of two types of expectations, represented by two different types of agents: fundamentalists and institutionalists $(F, I$, respectively). Fundamentalist expect that the exchange rate $(s)$ will return to its equilibrium level $(\bar{s})$, at a adjustment speed equal to $v$. The equilibrium level is defined in terms of PPP: $\bar{s}=p-p^{*}$, where $p, p^{*}$ stand for the (log) domestic and foreign price index, respectively. Institutionalists (A.3) form their expectation, taking into account the existence of a target zone for the exchange rate and they believe that the exchange rate will always be defended, such that the target zone is perfectly credible. As a result, their expectactions are determined by the position of the exchange rate in the band ( $\left.s^{\prime}\right)$. Krugman (1990) and Froot \& Obstfeld (1991) show that the commitment of the authorities affect exchange rate expectations throughout the band: the closer the exchange rate is to the upper limit-s, (lower limit-s.) the larger appreciation (depreciation) is expected; at the limits of fluctuation the curve is tangent, such that expectations are non-linear with respect to the position of the exchange rate in the band. Figure A.l shows the expectations of both agents, with respects'.

Given both types of expectations, the market chooses the relative weight of each, such as to minimize the forecast errors, subject to (A.1) and the consideration of the past information by the market. We assume that the market places more weight on the recent past (hence the discounting parameter $\lambda<1)$. This optimization process results in the Discounted Least Squares (DLS) computation of the relative weight given to the fundamentalists $(w)$, presented in (A.4), where $\Delta s$ are the effective exchange rate changes.

The essential point of the model is the existence of a target zone while divergences remain in the economies. While the expectations of the institutionalists are static with respect to the position of the exchange rate in the band, fundamentalists expectations change with time, because $\bar{s}$, our fundamentals measure, is assummed to follow a random walk with drift $\mu$. This drift can be regarded as the expected inflation differentials. Therefore, the equilibrium drifts away from the central parity at an annual expected rate of $\mu$, as the slashed lines in figure A.I show. We can easily see that after some time, the exchange rate is driven by two opposing forces in the case of positive deviations from the central parity: institutionalists expect an appreciation of the currency and fundamentalists expect a depreciation which, for a given $s^{\prime}$, is larger as time goes by.

The dynamics of the process are generated by the assumption that the 
market has not a perfect knowledge of how the exchange rate is actually determined, such that it makes its guess according to its beliefs, represented by the models of fundamentalists and institutionalists. However, the exchange rate is actually determined by the motion equation (A.6), which permits the existence of fads and waves of opinion through the parameter $\theta$

Exchange rate trajectories can be generated endogeneously from equations (A.1-A.6). The plots will show that the exchange rate eventually reaches the band, so that interventions to defend the parities are necessary. This raises the issue of the sustainability of the band, since interventions will drain the stock of reserves of the Central Bank. Thus, the model is closed with a collapse condition-proved in the mentioned paper- which states that for positive misalignments $(\bar{s}-s>0)$, the band will collapse when two consecutive interventions are necessary, i.e, when the exchange rate does not re-enter the band after one intervention.

The simulations in the figures A.2, A.3 represent drifts equal to $1 \%, 2 \%$, In annual terms, respectively, that is inflation differentials of one and two points, respectively $)^{3}$; the periods displayed in the graphs, can be regarded as months. We can conclude that the zone allows a wide divergence between the temporal trajectory of the fundamentals $(\bar{s})$ and the effective exchange rate; this divergence can be observed both in terms of time and of magnitude. The magnitude of the divergence represents the overvaluation allowed by the target zone. As a consequence of the temporal divergence, the target zone can last much longer than the fundamentals would imply, though the zone will eventually collapse. We can also see in the figures that the larger the drift, the sooner the zone will collapse

\section{Endogenous drift}

The model can be easily extended to allow for deflationary effects of devaluations, that is, for the consideration of an endogenous drift in the fundamentals. Letting the domestic price index be a weighted average of national $\left(p_{n}\right)$ and foreign prices $\left(p_{n}{ }^{*}\right): p=h p_{n}+(1-h) p_{n}{ }^{*}$, where $h$ is the relative contribution of national goods to the domestic price index, and assumming that the national component of the price index adjust for previous inflation, we can see that positive misalignments exert a deflationary bias on prices.

\footnotetext{
${ }^{3}$-The rest of the parameters are $\sigma_{5}=0.05 \mu, \sigma_{s}=0.001, v=0.5, \theta=10, \lambda=0.8$. For details, see the mentioned reference.
} 
Taking into account that the equilibrium exchange rate is defined on a PPP basis, we can write:

$$
\text { (endogenous drift) } \quad \Delta \mu_{t}=(h-1)\left[\Delta\left(\bar{s}_{t-1}-s_{t-1}\right)\right]
$$

The parameter $h$ can be considered as a structural parameter of the economy and it is negatively related to the degree of openness of the country: for a given misalignment, the smaller $h$, the larger the deflationary effect of the exchange rate overvaluation, through the reduction in the drift; hence, we will refer to $1-h$ as the deflation parameter. Figures A.4,5 show the exchange rate realizations of the exchange rate process for two different parameters $(1-h=5 \%, 1-h=15 \%$, respectively) for the same initial drift $(\mu=1 \%)$ as the former examples. We observe that the equilibrium exchange rate diverges more slowly and it even becomes stationary in the second case, due to the reduction in the inflation differential; consequently, the collapse of the target zone is postponed.

\section{Convergence bands}

The reform of the EMS and the incorporation of the proposed convergence bands would not change esentially our model. However, it should be noted that, with respect to figure A.1, the central parity will shift in time and the width of the bands would be variable. As a consequence, for a given set of parameters and asumming $\beta<1$, the shift of the fundamentalists expectations with respect to the central parity per unit of time is expected to be equal to $\beta \mu$. Regarding, institutionalists' expectations, the narrowing of the bands, derived from convergence would imply changes in the slope of the curve, which would become steeper. 


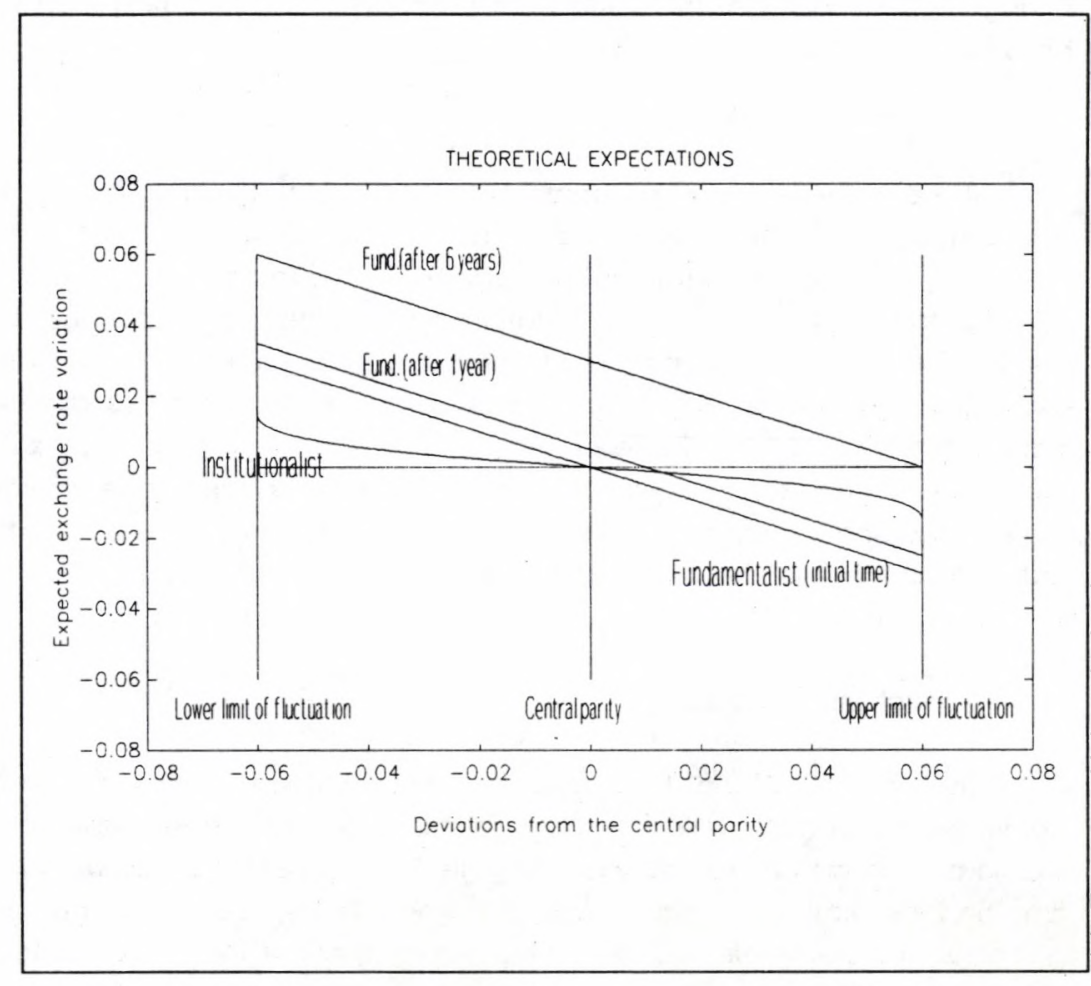

Fig A.1.- Exchange rate expectations: Fundamentalists and institutionalists.

Fundamentalists have linear expectations but, if there exists divergence in the fundamentals, their expectations are not constant with respect to the position of the exchange rate in the band. Institutionalists have non-linear expectations which are constant with respect to the exchange rate position within the band. 

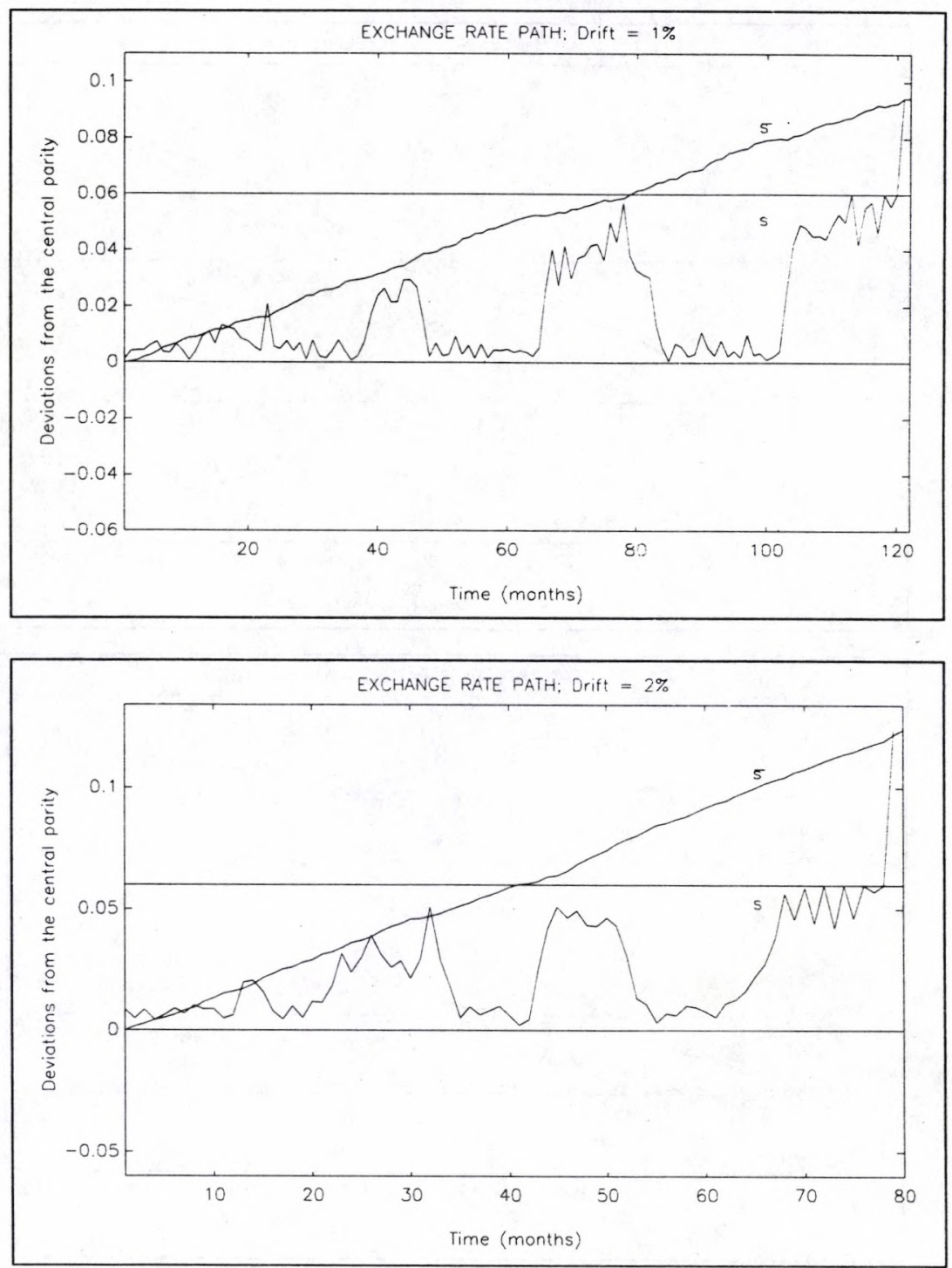

Fig A.2,3-Exchange rate trajectories simulated by the model. The solid line represents the equilibrium and the slashed line the path of the effective exchange rates generated in the simulations. The central parity and upper band are also displayed. The target zone collapses when the collapse condition is fulfilled. 

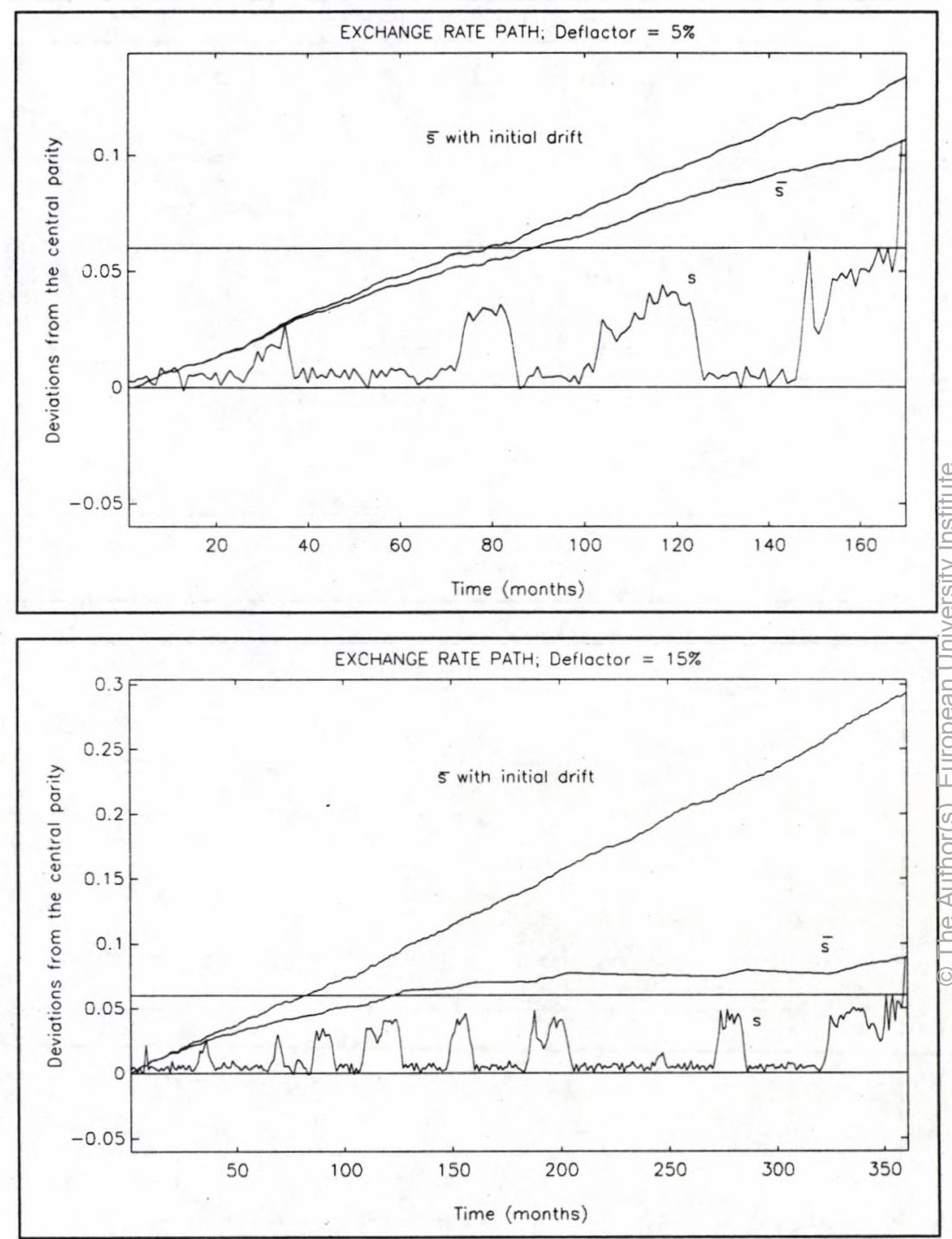

Fig A.4,5-Consideration of an endogenous drift in the model, through the overvaluation effect (1-h equal $5 \%$ and $15 \%$, respectively). The drift is set equal to $1 \%$. The slashed line displays the effective equilibrium exchange rate, which conveys the effect of overvaluation; this is compared with the equilibrium exchange rate if the overvaluation effect would have been dismissed. Finally, the effective exchange rate is also displayed: it can observed that the collapse period is postponed. 


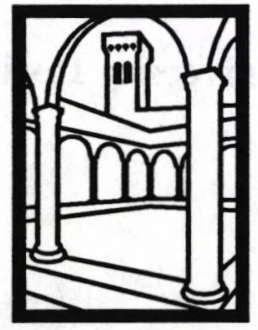

EUI

WORKING

PAPERS

EUI Working Papers are published and distributed by the

European University Institute, Florence

Copies can be obtained free of charge

- depending on the availability of stocks - from:

The Publications Officer

European University Institute

Badia Fiesolana

I-50016 San Domenico di Fiesole (FI)

Italy 


\section{Publications of the European University Institute}

To The Publications Officer

European University Institute

Badia Fiesolana

I-50016 San Domenico di Fiesole (FI) - Italy

Telefax No: $+39 / 55 / 573728$

From

Name

Address.

Please send me a complete list of EUI Working Papers

$\square$ Please send me a complete list of EUI book publications

$\square$ Please send me the EUI brochure Academic Year 1994/95

Please send me the following EUI Working Paper(s):

No, Author

Title:

No, Author

Title:

No, Author

Title:

No, Author

Title:

Date

Signature 


\section{Working Papers of the Robert Schuman Centre}

RSC No. 94/1

Fritz W. SCHARPF

Community and Autonomy Multilevel

Policy-Making in the European Union

RSC No. 94/2

Paul MCALEAVEY

The Political Logic of the European

Community Structural Funds Budget:

Lobbying Efforts by Declining Industrial

Regions

RSC No. 94/3

Toshihiro HORIUCHI

Japanese Public Policy for Cooperative

Supply of Credit Guarantee to Small Firms -

Its Evolution Since the Post War and Banks'

Commitment

RSC No. 94/4

Thomas CHRISTIANSEN

European Integration Between Political

Science and International Relations Theory:

The End of Sovereignty

RSC No. 94/5

Stefaan DE RYNCK

The Europeanization of Regional

Development Policies in the Flemish Region

RSC No. 94/6

Enrique ALBEROLA ILA

Convergence Bands: A Proposal to Reform

the EMS in the Transition to a Common

Currency 


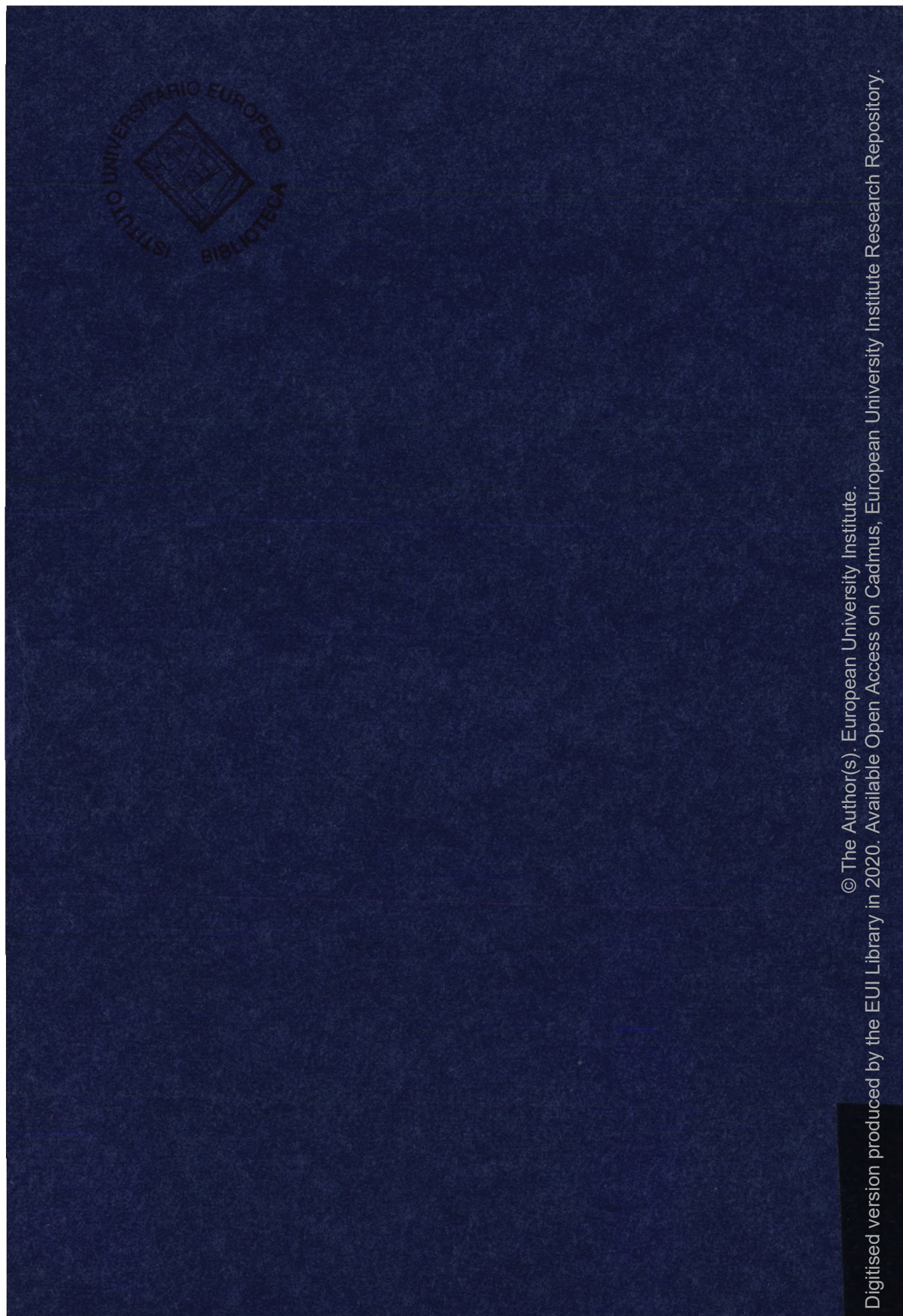

